\title{
Penggunaan Buku KIA, Keikutsertaan Kelas Ibu Hamil, Penggunaan Teknologi Informasi dan Peran Bidan dengan Pemenuhan Standar Minimal Kunjungan ANC pada Ibu Hamil
}

\author{
Yusta Tiya Mariadi ${ }^{1}$, Hidayani ${ }^{2}$ \\ ${ }^{1,2}$ Program Studi Kebidanan Program Sarjana Terapan Sekolah Tinggi Ilmu Kesehatan Indonesia Maju \\ Jln.Harapan No 50, Lenteng Agung-Jakarta Selatan 12610. Indonesia \\ Email: ${ }^{1}$ yustatiyamariadi@gmail.com, ${ }^{2}$ hidayani@gmail.com
}

\begin{abstract}
Abstrak
Tujuan Penelitian ini untuk mengetahui hubungan penggunaan buku kia, keikutsertaan kelas ibu hamil, penggunaan teknologi informasi dan peran bidan dengan pemenuhan standar minimal kunjungan ANC pada Ibu Hamil. Penelitian ini dilakukan di Puskesmas Simpang Empat Kayu Lapis Kabupaten Sekadau Provinsi Kalimantan Barat. Penelitian dilakukan pada bulan Maret 2018. Populasi dalam penelitian ini sebanyak 417 ibu hamil dan sampel berdasarkan perhitungan rumus slovin sebesar 81 responden. Penelitian ini menggunakan metode survei melalui pendekatan cross sectional dengan data primer yaitu menggunakan kuesioner. Hasil uji statistik didapatkan nilai $\mathrm{P}$ value $=0,003$ berarti $\mathrm{p}$ value $<\alpha(0,05)$, sehingga dapat disimpulkan ada hubungan penggunaan buku KIA dengan pemenuhan standar minimal kunjungan ANC Pada Ibu Hamil. P value $=0,000$ dapat disimpulkan ada hubungan keikutsertaan kelas ibu hamil dengan pemenuhan standar minimal kunjungan ANC. $\mathrm{P}$ value $=0,027$ dapat disimpulkan ada hubungan penggunaan teknologi informasi dengan pemenuhan standar minimal kunjungan ANC. $\mathrm{P}$ value $=0,006$ ada hubungan peran bidan dengan pemenuhan standar minimal kunjungan ANC. Kesimpulannya Hubungan Penggunaan Buku Kia, Keikutsertaan Kelas Ibu Hamil, Penggunaan Teknologi Informasi Dan Peran Bidan dengan Pemenuhan Standar Minimal Kunjungan ANC Pada Ibu Hamil Di Puskesmas Simpang Empat Kayu Lapis Kabupaten Sekadau Provinsi Kalimantan Barat Tahun 2017. Saran Ibu hamil harus mengikuti kelas ibu hamil untuk dapat menambah informasi tentang kehamilan.
\end{abstract}

Kata Kunci : : ANC, Bidan, Buku KIA, Informasi, Kelas

\begin{abstract}
The purpose of this research is to know the relationship of kia book usage, maternal class participation, use of information technology and role of midwife with fulfillment of minimum standard of ANC visit to pregnant mother. This research was conducted at Simpang Empat Kayu Lapis Public Health Center of Sekadau Regency, West Kalimantan Province. The study was conducted in March 2018. The population in this study were 417 pregnant women and the sample based on the calculation of slovin formula of 81 respondents. This research use survey method through cross sectional approach with primary data that is using questioner. Result of statistic test got value $P$ value $=0,003$ mean $p$ value $<(0,05)$, so it can be concluded there is relation of usage of KIA book with fulfillment standard minimum visit ANC at pregnant mother. $P$ value $=0.000$ can be concluded there is relation of class participation of pregnant mother with fulfill minimum standard of visit of ANC. $P$ value $=$ 0,027 can be concluded there is relation of usage of information technology with fulfillment standard minimum visit of ANC. $P$ value $=0,006$ there is relation of role of midwife to fulfill minimum standard of visit of ANC. Conclusion Relationship Use of Kia Books, Pregnancy Classroom Participation, Use of Information Technology And Role of Midwife with Minimum Standard Fulfillment of ANC Visit at Pregnant Women at Simpang Empus Puskesmas Simple Village of Sekadau Regency, Province of West Kalimantan Year 2017. Suggestion Pregnant mother must follow class of pregnant mother to be able add information about pregnancy.
\end{abstract}

Keywords: ANC, Information, KIA Book, Midwife, Pregnant. 


\section{Pendahuluan}

Keberhasilan upaya kesehatan ibu, di antaranya dapat dilihat dari indikator Angka Kematian Ibu (AKI). AKI adalah jumlah kematian ibu selama masa kehamilan, persalinan dan nifas yang disebabkan oleh kehamilan, persalinan, dan nifas atau pengelolaannya tetapi bukan karena sebabsebab lain seperti kecelakaan, terjatuh, dll di setiap 100.000 kelahiran hidup. Indikator ini tidak hanya mampu menilai program kesehatan ibu, terlebih lagi mampu menilai derajat kesehatan masyarakat, karena sensitifitasnya terhadap perbaikan pelayanan kesehatan, baik dari sisi aksesibilitas maupun kualitas. Penurunan AKI di Indonesia terjadi sejak tahun 1991 sampai dengan 2007, yaitu dari 390 menjadi 228. Namun demikian, SDKI tahun 2012 menunjukkan peningkatan AKI yang signifikan yaitu menjadi 359 kematian ibu per 100.000 kelahiran hidup. AKI kembali menujukkan penurunan menjadi 305 kematian ibu per 100.000 kelahiran hidup berdasarkan hasil Survei Penduduk Antar Sensus. ${ }^{1}$

Antenatal care (ANC) adalah pengawasan sebelum persalinan terutama ditujukan pada pertumbuhan dan perkembangan janin dalam Rahim. Antenatal care adalah untuk memfasilitasi hasil yang sehat dan positif bagi ibu maupun bayinya dengan cara membina hubungan saling percaya dengan ibu, mendeteksi komplikasi-komplikasi yang dapat mengancam jiwa, mempersiapkan kelahiran, dan memberikan pendidikan asuhan antenatal penting untuk menjamin agar proses alamiah tetap berjalan normal selama kehamilan. Kehamilan dapat menjadi masalah atau komplikasi setiap saat. Sekarang ini secara umum telah diterima bahwa setiap saat kehamilan membawa resiko bagi ibu, memperkirakan bahwa sekitar $15 \%$ dari seluruh wanita yang hamil akan berkembang menjadi komplikasi yang berkaitan dengan kehamilannya serta mengancam jiwanya. ${ }^{2}$

Semua ibu hamil dianjurkan agar memeriksakan kesehatan dirinya sedini mungkin. Pemeriksaan kehamilan dilakukan minimal empat kali, yaitu pada trimester I: satu kali, trimester II: satu kali, trimester III: dua kali. Pada ibu hamil resiko tinggi pemeriksaan dilakukan lebih sering dan intensif. Melalui pemeriksaan ini, perkembangan kesehatan ibu dapat diketahui. Bila ditemukan adanya gangguan kesehatan, tindakan dapat dilakukan sesegera mungkin. ${ }^{3}$

Sebagian besar kematian ibu disebabkan oleh penyebab langsung yaitu perdarahan, infeksi, eklampsia, persalinan lama dan abortus, komplikasi abortus. Disamping itu kematian ibu juga dilatarbelakangi oleh rendahnya tingkat sosial ekonomi, tingkat pendidikan dan peran perempuan, faktor sosial budaya serta faktor transportasi, yang semuanya berpengaruh pada munculnya dua keadaan yang tidak menguntungkan, yaitu: pertama, (3T) Terlambat (terlambat mengenal tanda bahaya dan mengambil keputusan, terlambat mencapai fasilitas kesehatan, dan terlambat mendapatkan pelayanan di fasilitas kesehatan); kedua, (4T) Terlalu (terlalu muda melahirkan, terlalu sering melahirkan, terlalu rapat jarak melahirkan, dan terlalu tua untuk melahirkan). Mortalitas dan mobilitas pada wanita hamil dan ibu bersalin adalah masalah terbesar di negara berkembang. Kematian saat melahirkan biasanya menjadi faktor utama mortalitas wanita muda pada puncak produktivitas. ${ }^{4}$

Teknologi informasi adalah sarana dan prasarana (hardware, software, useware) sistem dan metode untuk memperoleh, mengirimkan, mengolah, menafsirkan, menyimpan, mengorganisasikan, dan menggunakan data secara bermakna. ${ }^{5}$ Teknologi informasi adalah hasil rekayasa manusia terhadap proses penyampaian informasi dari pengirim ke penerima sehingga pengiriman informasi akan lebih cepat, lebih luas sebarannya, dan lebih lama penyimpanannya. ${ }^{6}$

Program pembangunan kesehatan yang dilaksanakan telah berhasil meningkatkan derajat kesehatan masayarakat secara cukup bermakna, walaupun masih dijumpai berbagai masalah san hambatan yang akan mempengaruhi pelaksanaan pembangunan kesehatan. Perubahan pemahaman konsep akan sehat dan sakit serta semakin maju IPTEK dengan informasi tentang determinan penyebab penyakit telah menggugurkan paradigma pembangunan kesehatan yang lama yang mengutamakan pelayanan kesehatan yang bersifat kuratif dan rehabilitatif. Paradigma pembangunan kesehatan yang baru yaitu Paradigma Sehat merupakan upaya untuk lebih meningkatkan kesehatan masyarakat yang bersifat proaktif. Paradigma sehat sebagai 
model pembangunan kesehatan yang dalam jangka panjang diharapkan mampu mendorong masyarakat untuk mandiri dalam menjaga kesehatan melalui kesadaran yang lebih tinggi pada pentingnya pelayanan kesehatan yang bersifat promotif dan preventif. ${ }^{7}$

Pada era komunikasi informasi ini media masa tidak dapat di gantikan untuk ikut serta dalam menyampaikan informasi penting kepada masyarakat umumnya dan ibu hamil khususnya. Media masa sangat efektif untuk menyampaikan informasi, terutama juga untuk mempromosikan hal-hal yang bersifat spesifik. ${ }^{8}$ Tenaga bidan merupakan salah satu tenaga kesehatan utama sebagai ujung tombak pembangunan kesehatan dalam upaya percepatan penurunan AKI dan AKB. Untuk itu dibutuhkan tenaga bidan yang terampil melakukan prosedural klinis dengan kemampuan analisis, kritis, dan tepat dalam penatalaksanaan asuhan pada perempuan. Keterlibatan bidan dalam asuhan normal dan fisiologis sangat menentukan demi penyelamatan jiwa ibu dan bayi oleh karena wewenang dan tanggung jawab profesionalnya sangat berbeda dengan tenaga kesehatan lain. Asuhan kebidanan kepada seorang perempuan selama fase kritis (hamil, bersalin, dan nifas) sangat menentukan kualitas kesehatan perempuan. Kondisi seorang perempuan selama menjalani kehamilan, persalinan dan masa nifas seharusnya terpantau oleh tenaga kesehatan khususnya bidan. ${ }^{9}$

Berdasarkan studi pendahuluan hasil wawancara kepada 10 ibu hamil diketahui bahwa 6 dari 10 orang ibu hamil belum mengerti maksud dari buku KIA, 7 dari 10 orang ibu hamil tidak pernah mengikuti kelas ibu hamil, 5 dari 10 orang mengunakan gadget sebagai informasi tentang kehamilan dan 6 dari 10 orang ibu hamil merasa bidan kurang berperan aktif dalam memberikan konseling kepada ibu hamil. Berdasarkan latar belakang maka peneliti tertarik untuk meneliti Hubungan Penggunaan Buku Kia, Keikutsertaan Kelas Ibu Hamil, Penggunaan Teknologi Informasi Dan Peran Bidan dengan Pemenuhan Standar Minimal Kunjungan ANC Pada Ibu Hamil Di Puskesmas Simpang Empat Kayu Lapis Kabupaten Sekadau Provinsi Kalimantan Barat Tahun 2017. Tujuan penelitian ini untuk mengetahui Hubungan Penggunaan Buku Kia, Keikutsertaan Kelas Ibu Hamil, Penggunaan Teknologi Informasi Dan Peran Bidan dengan
Pemenuhan Standar Minimal Kunjungan ANC Pada Ibu Hamil Di Puskesmas Simpang Empat Kayu Lapis Kabupaten Sekadau Provinsi Kalimantan Barat Tahun 2017.

\section{Metode}

Jenis penelitian ini termasuk analitik dengan metode survei melalui pendekatan cross sectional yaitu suatu penelitian untuk mempelajari dinamika korelasi antara faktorfaktor risiko dengan efek dengan cara pendekatan, observasi, dan pengumpulan data pada suatu saat itu. ${ }^{10}$ Digunakan untuk mengukur Hubungan Buku Kia, Kelas Ibu Hamil Dan Peran Teknologi Informasi, Peran Bidan Terhadap Pemenuhan Standar Minimal Kunjungan ANC Pada Ibu Hamil di Puskesmas Simpang Empat Kayu Lapis Kabupaten Sekadau Provinsi Kalimantan Barat Tahun 2017.

Populasi adalah keseluruhan objek penelitian atau subyek yang diteliti. ${ }^{11}$ Dalam penelitian ini populasi yang diambil adalah seluruh ibu hamil yang berkunjung ke di Puskesmas Simpang Empat Kayu Lapis Kabupaten Sekadau Provinsi Kalimantan Barat Tahun 2017 dan telah mendapatkan pelayanan antenatal care dengan populasi Ibu hamil sebanyak 417 ibu hamil.

Sampel adalah sebagian populasi yang diambil dari seluruh objek yang diteliti dan dianggap mewakili seluruh populasi. ${ }^{12}$ Sampel dalam penelitian ini adalah ibu hamil di Puskesmas Simpang Empat kayu Lapis Kabupaten Sekadau. Cara pengambilan sampel dengan systematic random sampling yaitu dengan membagi jumlah atau anggota populasi dengan perkiraan jumlah sampel yang diinginkan,

Kriteria insklusi adalah karakteristik umum subjek penelitian dari suatu populasi target yang terjangkau yang akan diteliti. ${ }^{12}$ Kriteria Insklusi dalam penelitian ini adalah Ibu hamil yang tinggal di wilayah puskesmas simpang empat kayu lapis sekurang-kurangnya 1 tahun. Bersedia menjadi responden. Sedang dalam keadaan sehat dan tidak terganggu jiwanya. Kriteria eksklusi adalah menghilangkan/ mengeluarkan subjek yang memenuhi kriteria insklusi dari penelitian karena sebab-sebab tertentu yaitu Ibu hamil sedang sakit. Ibu hamil tidak bersedia atau menolak menjadi responden. Kriteria non insklusi adalah karakteristik yang tidak 
termasuk dalam penelitian yaitu Ibu hamil yang tidak tinggal di wilayah puskesmas simpang empat kayu lapis sekurang-kurangnya 1 tahun.

Instrumen penelitian ini adalah alat atau fasilitas yang digunakan oleh peneliti dalam mengumpulkan data agar pekerjaanya lebih mudah dan hasilnya lebih baik sehingga lebih mudah diolah. Instrumen yang digunakan adalah angket atau kuesioner, yaitu sejumlah pertanyaan tertulis yang digunakan untuk memperoleh informasi dari responden dalam arti laporan tentang pribadinya atau hal-hal yang ia ketahui. ${ }^{13}$

Validitas berasal dari kata validity yang berarti sejauh mana ketetapan serta kecermataan suatu alat ukur dalam mengukur suatu data. Instrument dikatakan valid jika dapat mengungkapkan data dari variable yang diteliti secara tepat. ${ }^{14}$ Tinggi rendahnya validitas instrument memperlihatkan sejauh mana data yang terkumpul tidak menyimpang dari gambaran tentang validitas yng dimaksud.

Reabilitas yakni indeks yang memperlihatkan sejauh mana suatu alat pengukuran dapat dipercaya atau dapat diandalkan. Alat ukur yang digunakan harus akurat dan tidak menyebabkan kesalahan dalam suatu pengukuran. Hal ini berarti memperlihatkan sejauh mana hasil pengukuran itu tetap konsisten atau tetap asas (ajeg) bila dilakukan pengkuran 2 kali atau lebih terhadap gejala yang sama, dengan meenggunakan alat ukur yang sama.

Analisis Univariat adalah untuk mengetahui distribusi frekuensi dan gambaran dari setiap variabel sehingga analisis berikutnya dapat berjalan lebih mudah. ${ }^{12}$ Dalam penelitian ini analisis univariat dilakukan untuk menganalisa variabel Buku Kia, Kelas Ibu Hamil Dan Peran Teknologi Informasi, Peran Bidan dan Pemenuhan Standar Minimal Kunjungan Anc Pada Ibu Hamil di Puskesmas Simpang Empat Kayu Lapis Kabupaten Sekadau Provinsi Kalimantan Barat Tahun 2017 Analisis data dilakukan dengan program SPSS (Statistical Product and Service Solution) versi 18.

Analisis bivariat yang dilakukan terhadap dua variabel yang diduga berhubungan atau berkorelasi. Penelitian ini menggunakan uji Chi Square karena data yang digunakan dalam bentuk data kategorik.
Analisa bivariat dilakukan untuk mengetahui Hubungan Buku Kia, Kelas Ibu Hamil Dan Peran Teknologi Informasi, Peran Bidan Terhadap Pemenuhan Standar Minimal Kunjungan ANC Pada Ibu Hamil di Puskesmas Simpang Empat Kayu Lapis Kabupaten Sekadau Provinsi Kalimantan Barat Tahun 2017.

\section{Hasil}

Tabel 1. Distribusi Frekuensi Pemenuhan Standar Minimal Kunjungan ANC, Penggunaan Buku KIA, Keikutsertaan Kelas Ibu Hamil, Penggunaan Teknologi Informasi, Peran bidan Pada Ibu Hamil di Puskesmas Simpang Empat Kayu Lapis Kabupaten Sekadau Provinsi Kalimantan Barat Tahun 2017

\begin{tabular}{lll}
\hline Variabel & $\begin{array}{l}\text { Frekuensi } \\
\text { ( f ) }\end{array}$ & $\begin{array}{l}\text { Presentase } \\
(\%)\end{array}$ \\
\hline $\begin{array}{l}\text { Pemenuhan } \\
\text { Standar Minimal }\end{array}$ & & \\
$\begin{array}{l}\text { Kunjungan ANC } \\
\text { Tidak Standar }\end{array}$ & 81 & 39,7 \\
$\begin{array}{l}\text { Standar } \\
\text { Penggunaan }\end{array}$ & 123 & 60,3 \\
Buku KIA & & \\
Kurang Baik & 107 & 52,5 \\
Baik & 97 & 47,5 \\
Keikutsertaan & & \\
Kelas Ibu Hamil & & \\
Tidak Aktif & 65 & 31,9 \\
Kurang Aktif & 85 & 41,7 \\
Aktif & 54 & 26,5 \\
Penggunaan & & \\
Teknologi & & \\
Informasi & & \\
Kurang Baik & 99 & 48,5 \\
Baik & 105 & 51,5 \\
Peran bidan & & 52,0 \\
Kurang Baik & 106 & 48,0 \\
Baik & 98 & \\
\hline
\end{tabular}

Sumber: Data Primer 2017

Berdasarkan Tabel 1 pemenuhan standar minimal kunjungan anc pada ibu hamil di Puskesmas Simpang Empat Kayu Lapis Kabupaten Sekadau Provinsi Kalimantan Barat Tahun 2017 sebanyak 127 (60,3\%) responden terstandar dalam kunjungan ANC dan 81 responden $(39,7 \%)$ tidak Standar dalam kunjungan ANC. Penggunaan Buku KIA pada ibu hamil di Puskesmas Simpang Empat Kayu Lapis Kabupaten Sekadau Provinsi Kalimantan Barat Tahun 2017 sebanyak 97 (47,5\%) responden baik dan 107 responden $(52,7 \%)$ kurang baik. Keikutsertaan Kelas Ibu Hamil 
Tabel 2. Hubungan Penggunaan Buku Kia, Keikutsertaan Kelas Ibu Hamil, Penggunaan Teknologi Informasi dan Peran Bidan dengan Pemenuhan Standar Minimal Kunjungan ANC pada Ibu Hamil di Puskesmas Simpang Empat Kayu Lapis Kabupaten Sekadau Provinsi Kalimantan Barat Tahun 2017

\begin{tabular}{|c|c|c|c|c|c|c|c|c|}
\hline \multirow{3}{*}{ Variabel } & \multicolumn{4}{|c|}{$\begin{array}{l}\text { Pemenuhan Standar } \\
\text { Kunjungan ANC } \\
\text { Tidak }\end{array}$} & & & \multirow{3}{*}{$P$ value } & \multirow{3}{*}{ OR } \\
\hline & \multicolumn{2}{|c|}{$\begin{array}{l}\text { Tidak } \\
\text { Terstandar }\end{array}$} & \multicolumn{2}{|c|}{ Terstandar } & \multicolumn{2}{|c|}{ Total } & & \\
\hline & $\mathbf{f}$ & $\%$ & $\mathbf{f}$ & $\%$ & $\mathbf{f}$ & $\%$ & & \\
\hline \multicolumn{9}{|l|}{ Penggunaan } \\
\hline \multicolumn{9}{|l|}{ Buku KIA } \\
\hline Kurang baik & 57 & 53,3 & 50 & 46,7 & 107 & 100 & \multirow{3}{*}{0.003} & \multirow{3}{*}{$\begin{array}{l}2,427 \\
(1,371-4,297)\end{array}$} \\
\hline Baik & 31 & 32 & 66 & 68 & 97 & 100 & & \\
\hline Jumlah & 88 & 43,1 & 116 & 56,9 & 204 & 100 & & \\
\hline \multicolumn{9}{|c|}{ Keikutsertaan } \\
\hline Tidak aktif & 51 & 78,5 & 14 & 21,5 & 65 & 100 & \multirow{4}{*}{0.000} & \multirow{4}{*}{0.000} \\
\hline Kurang aktif & 23 & 27,1 & 62 & 72,9 & 85 & 100 & & \\
\hline Aktif & 14 & 25,9 & 40 & 74,1 & 54 & 100 & & \\
\hline Jumlah & 88 & 43,1 & 116 & 56,9 & 204 & 100 & & \\
\hline \multicolumn{9}{|l|}{$\begin{array}{l}\text { Penggunaan } \\
\text { teknologi } \\
\text { informasi }\end{array}$} \\
\hline Kurang baik & 51 & 51,5 & 48 & 48,5 & 99 & 100 & \multirow{4}{*}{0.027} & \multirow{3}{*}{$\begin{array}{l}1,953 \\
(1,113-3,425)\end{array}$} \\
\hline Baik & 37 & 35,2 & 68 & 64,8 & 105 & 100 & & \\
\hline Jumlah & 88 & 43,1 & 116 & 56,9 & 204 & 100 & & \\
\hline \multicolumn{8}{|l|}{ Peran bidan } & \\
\hline Kurang baik & 56 & 52,8 & 50 & 47,2 & 106 & 100 & \multirow{3}{*}{0.006} & \multirow{3}{*}{$\begin{array}{l}2,310 \\
(1,308-4,080)\end{array}$} \\
\hline Baik & 32 & 32,7 & 66 & 67,3 & 98 & 100 & & \\
\hline Jumlah & 88 & 43,1 & 116 & 56,9 & 204 & 100 & & \\
\hline
\end{tabular}

Sumber: Data Primer 2017

pada ibu hamil di Puskesmas Simpang Empat Kayu Lapis Kabupaten Sekadau Provinsi Kalimantan Barat Tahun 2017 sebanyak 85 responden $(41,7 \%)$ kurang aktif, 65 responden $(31,7 \%)$ tidak aktif, dan $54(26,5 \%)$ responden aktif. Penggunaan Teknologi Informasi pada ibu hamil di Puskesmas Simpang Empat Kayu Lapis Kabupaten Sekadau Provinsi Kalimantan Barat Tahun 2017 sebanyak 105 (51,5\%) responden baik dan 99 responden $(48,5 \%)$ kurang baik. Peran bidan sebanyak 98 (48\%) responden baik dan 106 responden (52\%) kurang baik.

Berdasarkan tabel 2 didapatkan hasil analisis hubungan penggunaan buku kia dengan pemenuhan standar minimal kunjungan ANC Pada Ibu Hamil di Puskesmas Simpang Empat Kayu Lapis Kabupaten Sekadau Provinsi Kalimantan Barat Tahun 2017 diperoleh bahwa ada sebanyak 57 responden $(53,3 \%)$ dari 107 responden penggunaan Buku KIA tidak baik dengan tidak standar dalam Minimal Kunjungan ANC sedangkan diantara responden yang penggunaan buku KIA baik ada sebanyak 66 responden (68\%) dari 97 responden dengan standar dalam Minimal Kunjungan ANC. Hasil uji statistik didapatkan nilai $\mathrm{P}$ value $=0,003$ berarti $\mathrm{p}$ value $<\alpha(0,05)$, sehingga dapat disimpulkan ada hubungan penggunaan buku kia dengan pemenuhan standar minimal kunjungan ANC Pada Ibu Hamil di Puskesmas Simpang Empat Kayu Lapis Kabupaten Sekadau Provinsi Kalimantan Barat Tahun 2017. Diperoleh nilai OR 2,427 artinya penggunaan buku KIA baik berpeluang 2,4 kali memenuhi standar Minimal Kunjungan ANC dibandingkan penggunaan Buku KIA kurang baik. Didapatkan hasil analisis hubungan keikutsertaan kelas ibu hamil dengan pemenuhan standar minimal kunjungan ANC Pada Ibu Hamil di Puskesmas Simpang Empat Kayu Lapis Kabupaten Sekadau Provinsi Kalimantan Barat Tahun 2017 diperoleh bahwa ada sebanyak 51 responden $(78,5 \%)$ dari 65 responden keikutsertaan kelas ibu hamil tidak aktif 
dengan tidak standar dalam Minimal Kunjungan ANC, ada sebanyak 23 responden $(27,1 \%)$ dari 85 responden keikutsertaan kelas ibu hamil kurang aktif dengan tidak standar dalam Minimal Kunjungan ANC dan ada sebanyak 14 responden $(25,9 \%)$ dari 54 responden keikutsertaan kelas ibu hamil aktif dengan tidak standar dalam Minimal Kunjungan ANC. Hasil uji statistik didapatkan nilai $\mathrm{P}$ value $=0,000$ berarti $\mathrm{p}$ value $<\alpha(0,05)$, sehingga dapat disimpulkan ada hubungan keikutsertaan kelas ibu hamil dengan pemenuhan standar minimal kunjungan ANC Pada Ibu Hamil di Puskesmas Simpang Empat Kayu Lapis Kabupaten Sekadau Provinsi Kalimantan Barat Tahun 2017. Didapatkan hasil analisis hubungan penggunaan teknologi informasi dengan pemenuhan standar minimal kunjungan ANC Pada Ibu Hamil di Puskesmas Simpang Empat Kayu Lapis Kabupaten Sekadau Provinsi Kalimantan Barat Tahun 2017 diperoleh bahwa ada sebanyak 51 responden $(51,5 \%)$ dari 99 responden penggunaan teknologi informasi kurang baik dengan tidak standar dalam Minimal Kunjungan ANC sedangkan diantara responden yang penggunaan teknologi informasi baik ada sebanyak 68 responden $(64,8 \%)$ dari 105 responden dengan standar dalam Minimal Kunjungan ANC. Hasil uji statistik didapatkan nilai $\mathrm{P}$ value $=0,027$ berarti $p$ value $<\alpha(0,05)$, sehingga dapat disimpulkan ada hubungan penggunaan teknologi informasi dengan pemenuhan standar minimal kunjungan ANC Pada Ibu Hamil di Puskesmas Simpang Empat Kayu Lapis Kabupaten Sekadau Provinsi Kalimantan Barat Tahun 2017. Diperoleh nilai OR 1,953 artinya penggunaan teknologi informasi baik berpeluang 1,9 kali memenuhi standar Minimal Kunjungan ANC dibandingkan penggunaan teknologi informasi kurang baik. Diapatkan hasil analisis hubungan peran bidan dengan pemenuhan standar minimal kunjungan ANC Pada Ibu Hamil di Puskesmas Simpang Empat Kayu Lapis Kabupaten Sekadau Provinsi Kalimantan Barat Tahun 2017 diperoleh bahwa ada sebanyak 56 responden $(52,8 \%)$ dari 106 responden peran bidan kurang baik dengan tidak standar dalam Minimal Kunjungan ANC sedangkan diantara responden yang peran bidan baik ada sebanyak 66 responden $(67,3 \%)$ dari 98 responden dengan standar dalam Minimal Kunjungan ANC. Hasil uji statistik didapatkan nilai $\mathrm{P}$ value $=0,006$ berarti $\mathrm{p}$ value $<\alpha(0,05)$, sehingga dapat disimpulkan ada hubungan peran bidan dengan pemenuhan standar minimal kunjungan ANC Pada Ibu Hamil di Puskesmas Simpang Empat Kayu Lapis Kabupaten Sekadau Provinsi Kalimantan Barat Tahun 2017. Diperoleh nilai OR 2,310 artinya peran bidan baik berpeluang 2,3 kali tidak memenuhi standar Minimal Kunjungan ANC dibandingkan peran bidan kurang baik.

\section{Pembahasan}

Hubungan Penggunaan Buku KIA dengan Pemenuhan Standar Minimal Kunjungan ANC Pada Ibu Hamil di Puskesmas Simpang Empat Kayu Lapis Kabupaten Sekadau Provinsi Kalimantan Barat Tahun 2017

Berdasarkan hasil analisis hubungan penggunaan buku kia dengan pemenuhan standar minimal kunjungan ANC Pada Ibu Hamil di Puskesmas Simpang Empat Kayu Lapis Kabupaten Sekadau Provinsi Kalimantan Barat Tahun 2017 diperoleh bahwa ada sebanyak 57 responden $(53,3 \%)$ dari 107 responden penggunaan Buku KIA tidak baik dengan tidak standar dalam Minimal Kunjungan ANC sedangkan diantara responden yang penggunaan buku KIA baik ada sebanyak 66 responden (68\%) dari 97 responden dengan standar dalam Minimal Kunjungan ANC. Hasil uji statistik didapatkan nilai $\mathrm{P}$ value $=0,003$ berarti $\mathrm{p}$ value $<\alpha(0,05)$, sehingga dapat disimpulkan ada hubungan penggunaan buku kia dengan pemenuhan standar minimal kunjungan ANC Pada Ibu Hamil di Puskesmas Simpang Empat Kayu Lapis Kabupaten Sekadau Provinsi Kalimantan Barat Tahun 2017. Diperoleh nilai OR 2,427 artinya penggunaan buku KIA kurang baik berpeluang 2,4 kali tidak memenuhi standar Minimal Kunjungan ANC dibandingkan penggunaan Buku KIA baik.

Hasil penelitian menunjukkan bahwa pengetahuan tentang ante natal care ibu hamil yang tinggi sebelum diberikan buku KIA adalah 29 (58\%). Sedangkan sebanyak 39 orang ( $78 \%$ ) pengetahuan tinggi tentang Antenatal care yang sudah 
diberi buku KIA lihat tabel 5. Hasil Penelitia korelasi ante natal care sebelum dan sesudah pemberian Buku KIA signifikansi 0.00 dan nilai " $r$ " 0.441 artinya korelasi sedang. ${ }^{15}$

Promosi Kesehatan dengan buku akan memberi dampak terhadap peningkatan pengetahuan ibu hamil. Manfaat yang lain buku KIA bagi petugas Kesehatan adalah pencatatan, pemantauan dan rujukan, sebagai alat komunikasi dan penyuluhan serta sebagai alat untuk mendeteksi secara didi adanya gangguan kesehatan ibu dan anak. Pengetahuan antenatalcare akan berpengaruh kepada perilaku sebagai hasil jangka menengah (intermediate impact) dari pendidikan kesehatan. Selanjutnya perilaku kesehatan akan berpengaruh kepada meningkatnya indikator kesehatan masyarakat sebagai keluaran (outcome) pendidikan kesehatan.

Menurut asumsi peneliti Buku Kesehatan ibu dan anak merupakan alat peraga (media) untuk promosi kesehatan. Buku ini terbukti dapat meningkatkan pemahaman dan pengetahuan kaum ibu khususnya mengenai kesehatan ibu dan anak. Buku KIA berisi catatan kesehatan ibu dan anak serta berbagai informasi yang sangat berguna untuk kesehatan ibu dan anak. Buku KIA bisa mendapat informasi tentang perkembangan ibu dan janin. Dari Buku KIA dijelaskan kapan sebaiknya ibu untuk melakukan pemeriksaan ANC dan dengan memahami buku KIA ibu pasti akan melakukan ANC secara rutin sesuai jadwal yang telah ditentukan.

Hubungan Keikutsertaan Kelas Ibu Hamil dengan Pemenuhan Standar Minimal Kunjungan ANC Pada Ibu Hamil di Puskesmas Simpang Empat Kayu Lapis Kabupaten Sekadau Provinsi Kalimantan Barat Tahun 2017

Berdasarkan Hasil uji statistik didapatkan nilai $\mathrm{P}$ value $=0,000$ berarti $\mathrm{p}$ value $<\alpha(0,05)$, sehingga dapat disimpulkan ada hubungan keikutsertaan kelas ibu hamil dengan pemenuhan standar minimal kunjungan ANC Pada Ibu Hamil di Puskesmas Simpang Empat Kayu Lapis Kabupaten Sekadau Provinsi Kalimantan Barat Tahun 2017.
Informasi hubungan keikutsertaan dalam kelas ibu hamil terhadap tanda bahaya kehamilan Terdapat hubungan yang bermakna antara keikutsertaan ibu dalam kelas ibu hamil tanda bahaya kehamilan $\mathrm{P}$ value $=0,031 \quad(p<0,05)$. Ibu hamil yang mengikuti kelas ibu hamil akan memiliki pengetahuan yang lebih baik dan sikap yang positif dalam mengenali tanda bahaya kehamilan. $^{16}$

Kelas ibu hamil adalah sarana untuk belajar tentang kesehatan bagi ibu hamil dalam bentuk tatap muka dalam kelompok yang bertujuan untuk meningkatkan pengetahuan, sikap, dan keterampilan ibu dan keluarga mengenai kehamilan, perawatan kehamilan, persalinan, perawatan nifas penyakit atau komplikasi saat hamilbersalin dan nifas, perawatan bayi baru lahir menggunakan buku KIA sebagai materi utama, dan senam ibu hamil. Tujuan pertemuan kelas ibu hamil yaitu meningkatkan pengetahuan, keterampilan ibu-ibu dan keluarga mengenai perawatan kehamilan, persalinan, nifas, penyakit dan komplikasi saat hamil, bersalin dan nifas, perawatan bayi baru lahir, dan senam hamil menggunakan buku KIA. ${ }^{17}$

Menurut asumsi peneliti keikutsertaan kelas ibu hamil berperan dalam meningkatkan pemenuhan standar minimal kunjungan ANC Pada Ibu Hamil karena dengan keikutsertaan kelas ibu hamil dapat menambah pengetahuan ibu hamil akan pentingnya pemeriksaan ANC selama kehamilan dan dapat mengetahui tanda tanda bahaya dalam kelahamilan. Pada Kelas ibu hamil bidan selalu menjelaskan kepada ibu untuk melakukan ANC secara rutin agar dapat memantau kondisi ibu dan janin.

Hubungan Penggunaan Teknologi Informasi dengan Pemenuhan Standar Minimal Kunjungan ANC Pada Ibu Hamil di Puskesmas Simpang Empat Kayu Lapis Kabupaten Sekadau Provinsi Kalimantan Barat Tahun 2017

Berdasarkan hasil uji statistik didapatkan nilai $\mathrm{P}$ value $=0,027$ berarti $\mathrm{p}$ value $<\alpha(0,05)$, sehingga dapat disimpulkan ada hubungan penggunaan teknologi informasi dengan pemenuhan standar minimal kunjungan ANC Pada Ibu Hamil di Puskesmas Simpang Empat Kayu 
Lapis Kabupaten Sekadau Provinsi Kalimantan Barat Tahun 2017. Diperoleh nilai OR 1,953 artinya penggunaan teknologi informasi kurang baik berpeluang 1,9 kali tidak memenuhi standar Minimal Kunjungan ANC dibandingkan penggunaan teknologi informasi baik. Analisis Faktor yang Berhubungan dengan Rendahnya Kunjungan (K4) Ibu Hamil di Puskesmas Bambu Apus, Jakarta Timur" diperoleh hasil uji statistik di peroleh nilai $p$-value $=0,017$, dengan demikian $P$ - value lebih kecil dari nilai Alpha (0.05), sehingga keputusan Họ ditolak. Hal inI berarti ada hubungan antara Sumber Informasi tentang kehamilan dengan kunjungan (K4) Ibu hamil Trimester III. ${ }^{18}$

Pada era komunikasi informasi ini media masa tidak dapat di gantikan untuk ikut serta dalam menyampaikan informasi penting kepada masyarakat umumnya dan ibu hamil khususnya. Media masa sangat efektif untuk menyampaikan informasi, terutama juga untuk mempromosikan halhal yang bersifat spesifik. Teknologi informasi adalah sarana dan prasarana (hardware, software, useware) sistem dan metode untuk memperoleh, mengirimkan, mengolah, menafsirkan, menyimpan, mengorganisasikan, dan menggunakan data secara bermakna. Teknologi informasi adalah hasil rekayasa manusia terhadap proses penyampaian informasi dari pengirim ke penerima sehingga pengiriman informasi akan lebih cepat, lebih luas sebarannya, dan lebih lama penyimpanannya.

Menurut asumsi peneliti pada saat ini penggunaan teknologi informasi adalah yang paling mudah untuk mendapatkan informasi secara cepat. Mudahnya akses informasi yang dilakukan ibu hamil dapat mengetahui bagaimana yang seharusnya ibu hamil lakukan dalam pemeriksaan kehamilannya. Penggunaan teknologi dapat berkomunikasi menggunakan Gadget/HP untuk menelfon petugas kesehatan agar mendapatkan informasi terkait jadwal kunjungan ANC. Penggunaan teknologi juga dapat diakses melalui internet untuk mengetahui kesehatan kehamilan.

\footnotetext{
Hubungan Peran Bidan dengan Pemenuhan Standar Minimal Kunjungan ANC Pada Ibu Hamil di Puskesmas Simpang Empat Kayu Lapis Kabupaten
}

\section{Sekadau Provinsi Kalimantan Barat Tahun 2017}

Berdasarkan hasil uji statistik didapatkan nilai $\mathrm{P}$ value $=0,006$ berarti $\mathrm{p}$ value $<\alpha(0,05)$, sehingga dapat disimpulkan ada hubungan peran bidan dengan pemenuhan standar minimal kunjungan ANC Pada Ibu Hamil di Puskesmas Simpang Empat Kayu Lapis Kabupaten Sekadau Provinsi Kalimantan Barat Tahun 2017. Diperoleh nilai OR 2,310 artinya peran bidan kurang baik berpeluang 2,3 kali tidak memenuhi standar Minimal Kunjungan ANC dibandingkan peran bidan baik.

Tentang penyebab rendahnya kelengkapan kunjungan antenatal care ibu hamil di Wilayah Kerja Puskesmas. Kunjungan ANC tidak lengkap banyak terdapat pada responden dengan peran bidan kurang baik $(80 \%)$ dibandingkan dengan per- an bidan yang baik $(34,6 \%)$. Hasil analisis bi- variat diketahui ada hubungan yang bermakna antara peran bidan dengan kelengkapan kun- jungan ANC ( $\mathrm{p}$-value = 0,003). Diketahui nilai ratio prevalency sebesar 2,23. Berarti variabel peran bidan merupakan salah satu faktor risiko dalam kelengkapan kunjungan ANC pada ibu hamil. Ibu yang memperoleh peran bidan yang kurang baik 2,23 kali berisiko melakukan kun- jungan ANC tidak lengkap dibanding ibu yang memperoleh peran bidan yang baik pada saat kunjungan ANC. ${ }^{19}$

Tenaga bidan merupakan salah satu tenaga kesehatan utama sebagai ujung tombak pembangunan kesehatan dalam upaya percepatan penurunan AKI dan AKB. Untuk itu dibutuhkan tenaga bidan yang terampil melakukan prosedural klinis dengan kemampuan analisis, kritis, dan tepat dalam penatalaksanaan asuhan pada perempuan. Keterlibatan bidan dalam asuhan normal dan fisiologis sangat menentukan demi penyelamatan jiwa ibu dan bayi oleh karena wewenang dan tanggung jawab profesionalnya sangat berbeda dengan tenaga kesehatan lain. Asuhan kebidanan kepada seorang perempuan selama fase kritis (hamil, bersalin, dan nifas) sangat menentukan kualitas kesehatan perempuan. Kondisi seorang perempuan selama menjalani 
kehamilan, persalinan dan masa nifas seharusnya terpantau oleh tenaga kesehatan khususnya bidan.

Menurut asumsi peneliti bahwa peran bidan memiliki kekuatan sebagai pencegahan dan pendorong seseorang berperilaku sehat terutama dalam kunjungan ANC. Bidan merupakan orang yang paling dipercaya dalah hal kesehatan pada ibu hamil. Baiknya peran bidan makan akan semakin baik pula kunjungan ANC pada ibu hamil.

\section{Kesimpulan}

Distribusi frekuensi pemenuhan standar minimal kunjungan anc pada ibu hamil di Puskesmas Simpang Empat Kayu Lapis Kabupaten Sekadau Provinsi Kalimantan Barat Tahun 2017 sebanyak 81 responden $(39,7 \%)$ tidak Standar dalam kunjungan ANC dan 127 (60,3\%) responden Standar dalam kunjungan ANC. Penggunaan Buku KIA sebanyak 107 responden (52,7\%) kurang baik dan 97 (47,5\%) responden baik. Keikutsertaan Kelas Ibu Hamil sebanyak 65 responden (31,7\%) tidak aktif, 85 responden $(41,7 \%)$ kurang aktif, dan 54 $(26,5 \%)$ responden aktif. Penggunaan Teknologi Informasi sebanyak 99 responden $(48,5 \%)$ kurang baik dan 105 (51,5\%) responden baik. Peran bidan sebanyak 106 responden (52\%) kurang baik dan 98 (48\%) responden baik.

Hasil uji statistik didapatkan nilai $\mathrm{P}$ value $=0,003$ berarti $\mathrm{p}$ value $<\alpha(0,05)$, sehingga dapat disimpulkan ada hubungan penggunaan buku KIA dengan pemenuhan standar minimal kunjungan ANC Pada Ibu Hamil di Puskesmas Simpang Empat Kayu Lapis Kabupaten Sekadau Provinsi Kalimantan Barat Tahun 2017.

Hasil uji statistik didapatkan nilai $\mathrm{P}$ value $=0,000$ berarti $p$ value $<\alpha(0,05)$, sehingga dapat disimpulkan ada hubungan keikutsertaan kelas ibu hamil dengan pemenuhan standar minimal kunjungan ANC Pada Ibu Hamil di Puskesmas Simpang Empat Kayu Lapis Kabupaten Sekadau Provinsi Kalimantan Barat Tahun 2017.

Hasil uji statistik didapatkan nilai $\mathrm{P}$ value $=0,027$ berarti $p$ value $<\alpha(0,05)$, sehingga dapat disimpulkan ada hubungan penggunaan teknologi informasi dengan pemenuhan standar minimal kunjungan ANC Pada Ibu Hamil di Puskesmas Simpang Empat Kayu Lapis Kabupaten Sekadau Provinsi Kalimantan Barat Tahun 2017.

Hasil uji statistik didapatkan nilai $\mathrm{P}$ value $=0,006$ berarti $\mathrm{p}$ value $<\alpha(0,05)$, sehingga dapat disimpulkan ada hubungan peran bidan dengan pemenuhan standar minimal kunjungan ANC Pada Ibu Hamil di Puskesmas Simpang Empat Kayu Lapis Kabupaten Sekadau Provinsi Kalimantan Barat Tahun 2017.

\section{Saran}

Bagi Ibu Hamil Ibu hamil harus mengikuti kelas ibu hamil untuk dapat menambah informasi tentang kehamilan, Ibu hamil yang memeriksakan kehamilannya baik kehamilan pertama maupun kehamilan yang berikutnya harus menggunakan Buku KIA, Ibu hamil dapat mengkases teknologi melalui gedget dengan akses internet untuk mengetahui dan menambah informasi tentang kondisi kehamilan, Ibu hamil selalu bertanya dan berkomunikasi kepada bidan tentang kondisi kehamilan pada setiap kali kunjungan ANC.

\section{Bagi Tempat Penelitian Bidan harus} lebih kooperatif dan selalu menginformasikan adanya kelas ibu hamil untuk meningkatkan kunjungan Pelayanan Antenatal Care (ANC) di Puskesmas Pembantu Desa Engkersik Sekadau.

Bagi penelitian selanjutnya Bagi penelitian selanjutnya untuk dapat dikembangkan dan diteliti secara mendalam dengan pendekatan kualitatif dan wawancara secara mendalam.

\section{Daftar Pustaka}

1. Kemenkes RI. Profil Kesehatan Indonesia tahun 2015. Jakarta: Kemenkes RI; 2015.

2. Yulaikhah, L. Seri Asuhan Kehamilan. Jakarta : ECG; 2010.

3. Mubarak W I dkk. Ilmu Keperawatan Komunitas Konsep dan aplikasi. Jakarta: Salemba Medika; 2011.

4. Sunarsih T dkk. Asuhanke hamilan untuk kebidanan. Jakarta: Salemba Medika; 2011.

5. Warsita B. Teknologi Pembelajaran: Landasan \&Aplikasinya. Jakarta: Rineka; 2008. 
6. Ishak. Pengelolaan Perpustakaan Berbasis Teknologi Informasi. Pustaka: Jurnal Studi Perpustakaan dan Informasi, Vol 4, No.2 pp 87; 2008.

7. Mukhsalmina A. Peran Tenaga Kesehatan Masyarakat Dalam Pencegahan Dan Penanggulangan PMS. http://mukhsal.blogspot.co.id/2013/01/perantenaga-kesehatan-masyarakat-dalam.html; 2013.

8. Soetjiningsih. Tumbuh Kembang Remaja Dan Permasalahannya. Jakarta: Sagung Seto; 2004.

9. Depkes RI. Keputusan Menteri Kesehatan Republik Indonesia No. 340/MENKES/PER/III tentang Klasifikasi Rumah Sakit. Jakarta: Depkes; 2010.

10. Hidayat AA. Metodologi penelitian dan teknis analisa data. Jakarta: Salemba; 2009.

11. Martoo N. Metode Penelitian Kuantitatif Analisis isi \& Analisis Data Sekunder. Jakarta: Rajagrafindo Persada; 2010.

12. Notoadmodjo S. Metodologi Kesehatan. Jakarta: Rineka Cipta; 2012.

13. Arikunto S. Prosedur Penelitian suatu Pendekatan Praktek. Jakarta: Rineka Cipta; 2010.

14. Sugiyono. Metode Penelitian Kuantitatif dan Kualitatif. Bandung: CV. Alfabeta; 2009.

15. Sumardino. Promosi Kesehatan Dengan Buku Kia Terhadap Peningkatan Pengetahuan Ibu Hamil Dan Ante Natal Care Di Puskesmas Ceper Klaten Tahun 2011. Surakarta: Kementerian Kesehatan Politeknik Kesehatan Jurusan Keperawatan; 2011.

16. Sasnitiari. Hubungan Keikutsertaan Ibu Dalam Kelas Ibu Hamil Dengan Pengetahuan Dan Sikap Terhadap Tanda Bahaya Dalam Kehamilan Di Kota Bogor. Jurnal Kesehatan Reproduksi, 8(2); 2017.

17. Widagdo L . Pemanfaatan Buku Kia Oleh Kader Posyandu: Studi Pada Kader Posyandu Di Wilayah Kerja Puskesmas Kedungadem Kabupaten Bojonegoro. Makara Kesehat [Internet].;13(1):39-47; 2009.

18. Nuraeni. Analisis Faktor yang Berhubungan dengan Rendahnya Kunjungan (K4) Ibu Hamil di Puskesmas Bambu Apus, Jakarta Timur. Jurnal Kesehatan Masyarakat, Vol.1, No.4 April 2016; 2016.

19. Fitrayeni. Tentang Penyebab Rendahnya Kelengkapan Kunjungan Antenatal Care Ibu Hamil Di Wilayah Kerja Puskesmas. Jurnal Kesehatan Masyarakat Andalas. ISSN 19783833. 10 (1)101-107; 2016. 